\title{
Leucocyte migration-inhibition in systemic lupus erythematosus
}

\author{
P. HUGHES, SHIRLEY HOLT, AND N. R. ROWELL \\ University Departments of Dermatology and Pathology, The General Infirmary at Leeds, Leeds LSI 3EX
}

Although the aetiology of systemic lupus erythematosus (SLE) remains unresolved, autoimmune phenomena are a very prominent feature of the disorder (Holman, 1965). While autoantibodies may be involved in the development of some of the lesions (Koffler, Schur, and Kunkel, 1967), they cannot by themselves be the prime cause of the disease (Beck, Oakley, and Rowell, 1966). Interest has recently centred once more on infective agents with reports of virus-like particles in many of the tissues of SLE (Norton, 1969; Bariety, Amor, Kahan, Balafrej, Callard, and Delbarre, 1971; Garancis, Komorowski, Bernhard, and Straumfjord, 1971) coming as a sequel to earlier reports of the isolation of mycoplasmas (Bartholomew, 1965; Jansson, Vainio, and Tuuri, 1971). It is well recognized that infection with such agents may precipitate autoimmune phenomena, such as haemolytic anaemia and thrombocytopenia (Dacie, 1962), and well established that the production of an experimental autoimmune lesion can require as a dual necessity the presence of both humoral and cell-mediated immune responses (Brown, Glynn, and Holborow, 1967). The leucocyte migration test has been shown to be an in vitro indicator of cell-mediated immunity (Søborg and Bendixen, 1967; Federlin, Maini, Russell, and Dumonde, 1971) and has provided evidence of cellular sensitization to organ specific antigens in Addison's disease (Nerup, Andersen, and Bendixen, 1970), active chronic hepatitis, and primary biliary cirrhosis (Miller, Smith, Mitchell, Reed, Eddleston, and Williams, 1972) as well as to a mycoplasma in rheumatoid arthritis (Williams, Brostoff, and Roitt, 1970). Using this test, we have investigated patients with SLE for evidence of cell-mediated immunity to a variety of antigens prepared from autologous, homologous and heterologous tissues and also from a culture of Mycoplasma fermentans.

\section{Material and methods}

PATIENTS

Sixteen women with SLE (Medical Research Council, 1961 ), having a mean age of $47 \cdot 9 \pm 14.9$ yrs, were investigated. The duration of the disease ranged from 2 years to 23 years, with five patients having been under regular outpatient review for a period of 10 years or more. This long period of follow-up and survival contributes to the unusually high mean age of this series. Four of the group were not receiving steroid treatment at the time the tests were performed, while in the remainder prednisone dosage ranged from 2.5 to $25 \mathrm{mg}$. daily. Controls consisted of seventeen normal healthy volunteers, four of whom were men, with a mean age of $35 \cdot 8 \pm 12 \cdot 1$ yrs.

PREPARATION OF ANTIGENS

Autologous lymphocytes were prepared from blood anticoagulated with 4 per cent. ethylenediaminetetra-acetic acid (1 part in 10) by centrifugation on a 'Ficoll-Triosil' gradient (Evans and Middleton, 1970). After washing with TC199 (Wellcome Reagents, Ltd.), the lymphocytes were lysed by freezing and thawing and the equivalent of $5 \times 10^{5}$ cells added as antigen to each migration chamber.

Mycoplasma fermentans (Cat. No. 10117, National Collection of Type Cultures, Colindale, London) was cultured by the method of Williams and others (1970). The harvested organisms were washed repeatedly with $0 \cdot 2 \mathrm{M}$ phosphate buffer $\mathrm{pH} 7 \cdot 2$ and then lysed by hypotonic shock and freezing and thawing (Razin, 1963). The resulting mycoplasmal 'antigen' was added to migration chambers to give a final concentration of $400 \mu \mathrm{g}$. protein per $\mathrm{ml}$.

Mitochondrial-rich and microsomal-rich fractions of human cadaver liver, obtained within 3 hours of death, were prepared by the method of Hogeboom (1955). The resulting fractions were added to migration chambers to give final concentrations of $800 \mu \mathrm{g}$. protein and $400 \mu \mathrm{g}$. protein per $\mathrm{ml}$. respectively.

Human myelin basic protein, prepared by the method of Eylar, Salk, Beveridge, and Brown (1969) and migrating as a single band on polyacrylamide gel electrophoresis, was kindly donated by Dr. J. Dickinson, Department of Pathology, University of Leeds, and used at a final concentration of $300 \mu \mathrm{g}$. protein per $\mathrm{ml}$. in the migration chambers.

Porcine thyroglobulin (Sigma Chemical Co.) was used at a concentration of $300 \mu \mathrm{g}$. protein per $\mathrm{ml}$. in the migration chambers.

LEUCOCYTE-MIGRATION TEST

The method used was the micro-modification devised by Federlin and others (1971). $30 \mathrm{ml}$. venous blood were anticoagulated by defibrination, and the erythrocytes then sedimented by adding $5 \mathrm{ml}$. of 'Plasmagel' (Laboratoire 
Roger Bellon, Neuilly, France). The supernatant leucocyte-rich plasma was pipetted off, centrifuged at $100 \mathrm{G}$ for $5 \mathrm{~min}$. and the resulting cell pellet resuspended and washed three times in TC199. The washed leucocytes were finally suspended in three volumes of TC199, aspirated into $10 \mu \mathrm{l}$. capillary tubes (Shandon Scientific, Ltd.) which were then sealed and centrifuged at $50 \mathrm{G}$ for $5 \mathrm{~min}$. Each capillary tube was broken cleanly at the fluid-cell interface and then mounted with silicone grease in plastic migration chambers (Sterilin, Ltd.) containing TC199 enriched with 20 per cent. foetal calf serum (Wellcome Reagents, Ltd.) and appropriate antigen. The chambers were sealed by silicone greased cover slips and incubated at $37^{\circ} \mathrm{C}$. for 22 to $24 \mathrm{hrs}$. All antigens were tested in quadruplicate. The extent of leucocyte migration was measured by weighing the projected image of the migrating cells on standard weight card. The extent of migration in the presence of antigen was expressed as a ratio (the 'migration index') of the migration occurring in control cultures.

\section{AUTOANTIBODIES}

The sera of the SLE patients were screened for the presence of rheumatoid factor, antinuclear, antimitochondrial, gastric parietal cell, thyroid microsomal, and thyroglobulin antibodies in the University Department of Immunology, The General Infirmary at Leeds.

\section{SERUM ENZYMES}

Serum glutamic pyruvate transaminase (SGPT), lactate dehydrogenase (LDH), and alkaline phosphatase levels in the SLE patients were determined by 'Auto-Analyser' in the Department of Chemical Pathology, St. James's (University) Hospital,_Leeds.

\section{Results}

The degree of leucocyte migration-inhibition in the SLE and control groups is shown in the Figure. Although the control group showed strikingly similar mean migration indices ranging from 0.84 to 0.94 for each of the six antigens tested, many of the individual indices showed some evidence of leucocyte migration-inhibition with the antigens examined. Such a response of normal controls to high concentrations of antigen, particularly those prepared from homologous tissues, has been noted in other studies (Miller and others, 1972; Calder, McLeman, Barnes, and Irvine, 1972) and has been further investigated by Weir and Suckling (1971).

By contrast, the patients with SLE showed a very significantly greater degree of leucocyte migrationinhibition with five of the six antigens tested, i.e. the Mycoplasma fermentans preparation, autologous lymphocytes, microsomal-rich and mitochondrialrich fractions of human liver and human myelin basic protein. The mean inhibition in all these five instances (migration indices of 0.53 to 0.60 ) was again strikingly uniform and again in marked contrast to the migration-inhibition produced by the porcine thyroglobulin which did not differ from the mean response of the control group. The test showed good reproducibility in that individual patients continued to give positive and very comparable results when re-examined at intervals of 3 to 6 months.

No correlation was found between the degree of

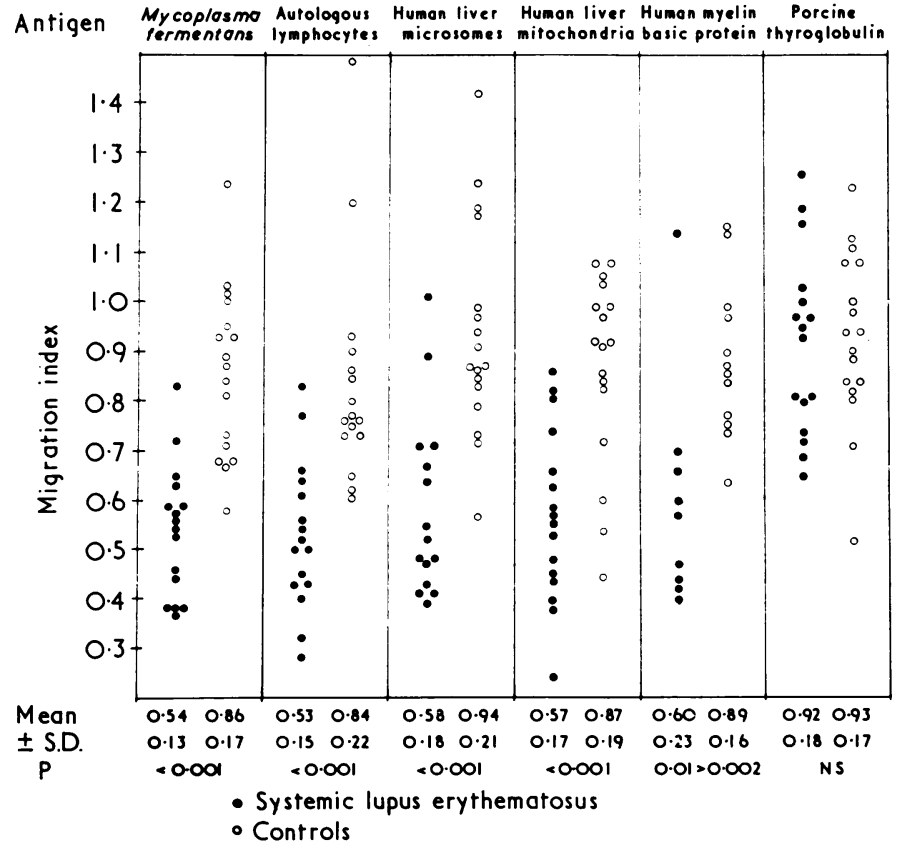

FIGURE Results of the leucocyte migration test 
migration-inhibition to any particular antigen in any patient and the pattern of visceral involvement, activity, or duration of the disease. Similarly, despite the high incidence of significant migration-inhibition with antigens prepared from human liver, estimations of the serum alkaline phosphatase, SGPT, and LDH were all within the normal range and failed to show any evidence of liver disease that might have been clinically occult.

Steroid dosage varied widely in the patients with SLE but once more showed no clear correlation with the extent of the leucocyte migration-inhibition.

The pattern of antibodies present at the time of the tests in the SLE group is shown in the accompanying Table. Apart from the expected high incidence of antinuclear antibodies, there is again no correlation with the migration-inhibition studies, the low incidence of antibodies to mitochondria contrasting particularly with the high incidence of leucocyte migration-inhibition produced by this antigen.

\section{Discussion}

Our investigation has shown that patients with SLE have a high incidence of significant leucocyte migration-inhibition against a wide range of antigens. Considerable evidence suggests that this test reflects a state of cell-mediated immunity (Søborg and Bendixen, 1967; Federlin and others, 1971) and additional support for the correctness of this interpretation in SLE is provided by an earlier report of macrophage migration-inhibition factor production in this disease by one of the antigens used in the present study (Field and Caspary, 1970). The normal leucocyte migration in the presence of porcine thyroglobulin serves to emphasize the significance of the inhibition produced by the other antigens, partly by establishing specificity and partly by illustrating that leucocytes in SLE can migrate normally in the presence of added foreign protein.

One can conclude that there is in SLE widespread (and abnormal) cellular hypersensitivity against antigens-some of which are autoantigens-as a complementary feature to the equally widespread (and abnormal) humoural responses that are so characteristic of the disorder. The observed pattern of migration-inhibition is, we suggest, most readily explained if it is regarded as indicating a loss of tolerance. The sensitization to autologous lymphocytes and homologous liver antigens and myelin basic protein is accounted for on this basis as is the contrasting lack of sensitization to the heterologous porcine thyroglobulin. The situation with the mycoplasmal preparation may well be different. Apart from the possibility of specific sensitization to a mycoplasma-isolation of which has been reported in SLE (Bartholomew, 1965; Jansson and others, 1971) - or a cross-reaction with an antigen shared with autologous tissues, there may also be sensitization, as in rheumatoid arthritis (Fröland and Gaarder, 1971), to aggregated immunoglobulins which have been incorporated into the mycoplasma membrane from the culture medium (Williams and others, 1970).

The present study does not show, however, any evidence of a correlation between the extent of the migration-inhibition and the pattern of visceral involvement or disease activity. The cell-mediated hypersensitivity revealed by the test cannot, therefore, be regarded as an index of cytotoxic lymphocyte activity in vivo-a disparity which has been noted in other investigations utilizing the test (Miller and others, 1972). One possible explanation for this disparity is that there may be serum factors present in vivo which are capable of inhibiting otherwise detectable auto-sensitization resulting from exposure to related cross-reacting antigens (Micklem, 1971).

It has, however, also been suggested that the prevention of autoimmune reactions is normally an important function of thymus-dependent $(\mathrm{T})$ lymphocytes both through specific feedback control of non-thymus derived (B) lymphocytes and through the maintenance of induced unresponsiveness (Allison, Denman, and Barnes, 1971). The persisting cellular sensitization to auto-antigens in SLE, as revealed by the present study, could, in this context, allow the emergence of cytotoxic lymphocytes as well as facilitating auto-antibody production through the cooperation of $\mathrm{T}$ and $\mathrm{B}$ lymphocytes. The underlying cause of such a defect in lymphocyte function remains uncertain, but may be, at least, partly genetic in origin. SLE certainly has a well-established familial incidence (Brunjes, Zike, and Julian, 1961) and association with specific HLA types (Grumet, Coukell, Bodmer, Bodmer, and McDevitt, 1971), while there is evidence that the lupus-like autoimmune disease of the NZB mouse also has a genetic basis (Ghaffar and Playfair, 1971). There is, however, evidence that infective agents may also be involved. NZB mice, even when reared under germ-free conditions, are heavily infected with murine leukaemia virus (East and Branca, 1969), while

Table Autoantibodies in sixteen patients with SLE

\begin{tabular}{|c|c|c|c|c|c|}
\hline Autoantibody & Antinuclear & Antimitochondrial & Gastric parietal cell & Antithyroid* & Rheumatoid factor \\
\hline Number positive & 13 & 1 & 0 & 4 & 8 \\
\hline
\end{tabular}

* Includes thyroglobulin and thyroid microsomal antibodies. 
virus-like particles have now been widely recognized in many of the tissues of human SLE (Norton, 1969; Bariety and others, 1971; Garancis and others, 1971). NZB mice also show a marked resistance to the induction of tolerance in both their $B$ and $T$ lymphocytes (Playfair, 1971; Jacobs, Gordon, and Talal, 1971) and, as autoantibodies and overt autoimmune disease appear, develop other signs of deteriorating function in their $T$ lymphocytes (Ghaffar, Krsiakova, and Playfair, 1970). It is, therefore, tempting to think that some persisting infective agent(s), especially in genetically predisposed individuals, could be a factor in the breakdown of tolerance and so precipitate the development of widespread autoimmune disease.

\section{Summary}

The leucocyte migration test was used to examine patients with systemic lupus erythematosus (SLE) for evidence of cell-mediated immunity to a wide range of autologous, homologous, and heterologous antigens. Sixteen patients with SLE and seventeen normal controls were tested for sensitivity to autologous lymphocytes, microsomal and mitochondrial fractions of human cadaver liver, human myelin basic protein, a preparation of Mycoplasma fermentans, and porcine thyroglobulin. Migration indices in the control group showed a uniform response with, in general, only minimal reactivity for each of the antigens tested. By contrast, the patients with SLE showed a significantly greater degree of migrationinhibition to autologous lymphocytes, the liver microsomes and mitochondria, the myelin basic protein, and the mycoplasmal preparation. Leucocyte migration in the presence of porcine thyroglobulin did not differ, however, from that in the normal controls. The findings indicate that there is in SLE widespread cell-mediated hypersensitivity, much of which is directed against both autologous and homologous antigens.

We thank Prof. G. P. McNicol, Dr. E. W. Jackson, and Dr. S. M. Rosen for access to patients under their care; Mr. R. A. Forster for excellent technical assistance; and Dr. R. B. Payne and Prof. G. Gowland for the estimation of serum enzymes and the detection of autoantibodies.

\section{References}

Allison, A. C., Denman, A. M., ANd Barnes, R. D. (1971) Lancet, 2, 135 (Cooperating and controlling functions of thymus-derived lymphocytes in relation to autoimmunity)

Bariety, J., Amor, B., Kahan, A., Balafrej, L., Callard, P., and Delbarre, F. (1971) Ibid., 2, 103 (Ultrastructural anomalies in peripheral-blood mononuclear cells from patients with S.L.E.)

Bartholomew, L. E. (1965) Arthr. and Rheum., 8, 376 (Isolation and characterization of mycoplasmas (PPLO) from patients with rheumatoid arthritis, systemic lupus erythematosus and Reiter's syndrome)

BeCK, J. S., OAKLey, C. L., AND Rowell, N. R. (1966) Arch. Derm., 93, 656 (Transplacental passage of antinuclear antibody. Studies in infants of mothers with systemic lupus erythematosus)

Brown, P. C., GlynN, L. E., AND Holborow, E. J. (1967) Immunology, 13, 307 (The dual necessity for delayed hypersensitivity and circulating antibody in the pathogenesis of experimental allergic orchitis in guinea-pigs)

Brunjes, S., Zike, K., AND Júlian, R. (1961) Amer. J. Med., 30, 529 (Familial systemic lupus erythematosus. A review of the literature with a report of ten additional cases in four families)

Calder, E. A., McLeman, D., Barnes, E. W., ANd IRvine, W. J. (1972) Clin. exp. Immunol., 12, 429 (The effect of thyroid antigens on in vitro migration of leucocytes from patients with Hashimoto's thyroiditis)

DACIE, J. V. (1962) In 'The Haemolytic Anaemias, Congenital, and Acquired', 2nd ed., Part II 'The auto-immune haemolytic anaemias', p. 585. Churchill, London

EAST, J., AND BRANCA, M. (1969) Clin. exp. Immunol., 4, 621 (Autoimmune reactions and malignant changes in germ-free New Zealand black mice)

Evans, C. A., AND Middleton, V. L. (1970) J. clin. Path., 23, 822 (Evaluation of methods for preparing pure lymphocyte suspensions from peripheral blood)

Eylar, E. H., Salk, J., Beveridge, G. C., and Brown, L. V. (1969) Arch. Biochem., 132, 34 (Experimental aulergic encephalomyelitis. An encephalitogenic basic protein from bovine myelin)

Federlin, K., MAINI, R. N., Russell, A. S., AND DumONDE, D. C. (1971) J. clin. Path., 24, 533 (A micro-method for peripheral leucocyte migration in tuberculin sensitivity)

Field, E. J., AND CASPARY, E. A. (1970) Lancet, 2, 1337 (Lymphocyte sensitisation. An in vitro test for cancer?)

Fröland, S. S., AND GAARDER, P. I. (1971) Ibid., 1, 1071 (Leucocyte-migration inhibition induced by IgG in rheumatoid arthritis)

Garancis, J. C., Komorowski, R. A., Bernhard, G. C., and Straumfjord, J. V. (1971) Amer. J. Path., 64, 1 (Significance of cytoplasmic microtubules in lupus nephritis)

Ghaffar, A., Krsiakova, M., AND PlayfaIR, J. H. L. (1970) Transplantation, 10, 432 (Deficient cell-mediated immunity in adult NZB mice)

- AND PlayfaIR, J. H. L. (1971) Clin. exp. Immunol., 8, 479 (The genetic basis of autoimmunity in NZB mice studied by progeny-testing)

Grumet, F. C., Coukell, A., Bodmer, J. G., Bodmer, W. F., AND McDevitt, H. O. (1971) New Engl. J. Med., 285, 193 (Histocompatibility (HL-A) antigens associated with systemic lupus erythematosus. A possible genetic predisposition to disease) 
НоGевоOм, G. H. (1955) 'Fractionation of cell components of animal tissues', in 'Methods in Enzymology', vol. 1, ed. S. P. Colowick and N. O. Kaplan, p. 16. Academic Press, New York

Holman, H. R. (1965) 'Systemic lupus erythematosus', in 'Immunological Diseases', ed. M. Samter, p. 737. Churchill, London

JACOBS, M. E., GoRDON, J. K., AND TALAL, N. (1971) J. Immunol., 107, 359 (Inability of the NZB/NZW F 1 thymus to transfer cyclophosphamide-induced tolerance to sheep erythrocytes)

JANsson, E., VAINIO, U., AND TUURI, S. (1971) Acta rheum. scand., 17, 223 (Cultivation of a mycoplasma from the bone marrow in systemic lupus erythematosus disseminatus)

Koffler, D., SChUR, P. H., AND KUNKel, H. G. (1967) J. exp. Med., 126, 607 (Immunological studies concerning the nephritis of systemic lupus erythematosus)

Medical ResearCh CounCIL (1961) Brit. med. J., 2, 915 (Treatment of systemic lupus erythematosus with steroids. Report to Medical Research Council by the Collagen Diseases and Hypersensitivity Panel)

MiCKLEM, H. S. (1971) 'The cellular basis of "self"--tolerance', in 'Immunological Tolerance to Tissue Antigens', ed. N. W. Nisbet and M. W. Elves, p. 237. Orthopaedic Hospital, Oswestry

Miller, J., Smith, M. G. M., Mitchell, C. G., Reed, W. D., EdDleston, A. L. W. F., ANd WiLliams, R. (1972) Lancet, 2, 296 (Cell-mediated immunity to a human liver-specific antigen in patients with active chronic hepatitis and primary biliary cirrhosis)

Nerup, J., ANDERSEN, V., AND BENDIXEN, G. (1970) Clin. exp. Immunol., 6, 733 (Anti-adrenal cellular hypersensitivity in Addison's disease. IV. In vivo and in vitro investigations on the mitochondrial fraction)

NorTon, W. L. (1969) J. Lab. clin. Med., 74, 369 (Endothelial inclusions in active lesions of systemic lupus erythematosus)

PlayfaiR, J. H. L. (1971) Immunology, 21, 1037 (Strain differences in the immune responses of mice. III. A raised tolerance threshold in NZB thymus cells)

RazIN, S. (1963) J. gen. Microbiol., 33, 471 (Osmotic lysis of mycoplasma)

SøвorG, M., AND BENDIXeN, G. (1967) Acta med. scand., 181, 247 (Human lymphocyte migration as a parameter of hypersensitivity)

WeIR, D. M., AND Suckling, D. E. J. (1971) Clin. exp. Immun., 8, 791 (Macrophage migration inhibition induced by tissue antigen in guinea-pigs)

Williams, M. H., Brostoff, J., AND RortT, I. M. (1970) Lancet, 2, 277 (Possible role of Mycoplasma fermentans in the pathogenesis of rheumatoid arthritis) 